\title{
Engaging women volunteers of high socioeconomic status in supporting socioeconomically disadvantaged tuberculosis patients in Chiang Rai, Thailand
}

\author{
Jintana Ngamvithayapong-Yanai, ab Sarmwai Luangjina, bupalert Nedsuwan, c Pacharee Kantipong, \\ Jirapohn Wongyaib and Nobukatsu Ishikawa ${ }^{a}$ \\ Correspondence to Jintana Ngamvithayapong-Yanai (email: jip@loxinfo.co.th and jintanajip@yahoo.com).
}

Problem: The 2008 tuberculosis (TB) surveillance of Chiang Rai Hospital, Chiang Rai, Thailand reported that $8.4 \%$ of Thai, $22.7 \%$ of hill tribe minority and $25 \%$ of migrant patients $(n=736)$ defaulted from treatment.

Context: TB patient management in Chiang Rai is complicated due to poverty and HIV stigma. A previous study shows unaffordable travel expense was one of the reasons of patient default.

Action: We engaged Chiang Rai women's organizations whose members are of high socioeconomic status to support poor TB patients financially and socially. A group of women formed a team to support these TB patients $(n=192)$ by raising and sustaining funds and providing home visits $(n=37)$. TB surveillance and patient-fund register data were used to evaluate TB treatment outcomes.

Outcome: The success of TB treatment was significantly higher for patients receiving financial support (relative risk [RR]: $1.351 ; 95 \%$ confidence interval $[\mathrm{Cl}] 1.20-1.53 ; P<0.000$ ). Lower death rates in all groups were observed among patients receiving financial support. However, financial assistance alone did not improve treatment outcomes for migrant patients. Thirty-seven patients (25 Thai, eight hill tribe, four migrants) who were visited by women volunteers at home achieved 95\% TB treatment success.

Discussion: It is possible to involve volunteers to support poor TB patients. Willingness to support TB patients was driven by presenting provincial TB epidemiology information, research data on the experience of poor patients and the inspiring experiences of other women volunteers. Future research should investigate the reasons for the high treatment success among patients who received home visits.

\section{PROBLEM}

Regardless of a country's economy or tuberculosis (TB) prevalence, TB is a disease associated with poverty, ${ }^{1}$ and Thailand is no exception. Although the World Bank has ranked Thailand as an upper-middle-income country, the income gap between the rich and the poor is one of the most unequal in Asia. ${ }^{2}$ The World Health Organization (WHO) classified Thailand as a country with high prevalences of TB, HIV and TB with HIV co-infection (TB/HIV). ${ }^{3}$ Since 1998, WHO has listed Thailand as one of the 22 high TB-burden countries. Chiang Rai, Thailand's northernmost province, has a high density of hill tribe minorities and migrants from Myanmar. Of the 1.2 million people in Chiang Rai, about 18460 people are living with HIV; the TB notification rate in 2011 was 153 per 100000 (23\% TB with HIV coinfection). The Chiang Rai provincial TB surveillance data indicates that, on average, one patient dies of TB every 36 hours in the province.

Chiang Rai Hospital (CRH), the largest provincial government hospital, provides free TB diagnosis and treatment for patients who declare that health-care costs are unaffordable. Patients are requested to visit the hospital biweekly or monthly, depending on their

\footnotetext{
The Research Institute of Tuberculosis, Japan Anti-tuberculosis Association, Tokyo, Japan

TB/HIV Research Foundation, Muang District, Chiang Rai, Thailand.

Chiang Rai Regional Hospital, Chiang Rai, Thailand.

Submitted: 26 October 2012; Published: 28 January 2013

doi: 10.5365/wpsar.2012.3.4.013
} 
clinical conditions. Although treatment is free, TB patient management in $\mathrm{CRH}$ is complicated due to poverty, HIV stigma, language and cultural differences, as well as the legal status of some patients. The 2007 TB surveillance of $\mathrm{CRH}(n=736)$ reported that $8.4 \%$ of Thai, $22.7 \%$ of hill tribe minority, and $25 \%$ of migrant patients, defaulted from treatment. Our previous study ${ }^{4}$ reported that a majority of TB patients had to borrow money during their TB treatment course (six to nine months). Unaffordable travel expense was referred to as a main cause of treatment interruption, especially for hill tribe and migrant patients. Due to language barriers, these cases had to be accompanied to the hospital, which doubled the travel expense. During the investigation into reasons for default from TB treatment, we learnt about the difficulties experienced by poor patients. Older children who lost their parents had to quit school and go to work; younger children were raised by elderly grandparents. ${ }^{5}$

\section{CONTEXT}

In 2008 we established the "Center for Sharing," a TB patient-fund at $\mathrm{CRH}$ providing travel and food support for those who needed it. The initial 100000 Thai baht (approximately US\$3300) was granted from the Stop TB partnership. ${ }^{6}$ Our greatest challenge was devising a way to sustain the patient-fund after the initial grant was exhausted.

\section{ACTION}

To ensure continuity of the patient-fund, we explored the feasibility of fund-raising in a sustainable manner by involving Chiang Rai women's organizations whose members are of high socioeconomic status. We obtained a list of women's organizations in Chiang Rai through an internet search, contacted the provincial social development and human security office and discussed our plans with the chair of a menopause clinic club. Subsequently, we organized the first workshop by inviting 33 women from nine women's organizations in Chiang Rai. The five-hour workshop included the following sessions:

- Pre- and post-workshop tests about TB;

- Information about TB disease;

- Chiang Rai TB epidemiology;

- Experiences of poor TB patients;
- TB control case studies on the role of women volunteers in India, Bangladesh, Indonesia and Japan; and

- Group discussion on "Can women's organizations in Chiang Rai contribute to TB care?"

The first workshop revealed most women were highly aware of the serious HIV situation in Chiang Rai, but they thought of TB as a disease of the past. Although the experiences of women volunteers from low-income countries were presented, the participants reported relating best to the Japanese volunteers' experiences. The slogan "Eradicate TB with women's hands and hearts" inspired the group, and they believed they could develop a similar project in Chiang Rai.

Two follow-up workshops to discuss and plan actions were organized. By the end of the third workshop a group was formed called "Women Volunteers to Eradicate TB." The group selected a chair, vice-chair, treasurer and secretariat and invited the TB and HIV doctors from $\mathrm{CRH}$ to be advisers. The volunteers performed two major activities to support TB patients: fund-raising for the TB patient-fund and home visits.

\section{Fund-raising for TB patient-fund}

The volunteers raised funds to support TB patients by organizing a charity gala dinner, selling products at provincial festivals and conferences and collecting donations from individual volunteers and women's organizations. The TB patient-fund staff identified patients who needed financial assistance for transportation and living expenses by interviewing TB patients with a simple poverty screening questionnaire. ${ }^{7}$ The questionnaire included the following: (1) Do you have health insurance? (2) Do you have less than US\$ 3 for the whole family or did you experience a food shortage during the last month? (3) Are you able to pay for travel to the TB clinic? (4) Do you have family members, friends or relatives to help when encountering a financial crisis? The support ranged from 100 to 4000 Thai baht per visit depending on the patient's circumstances.

\section{Home visit}

In addition to receiving financial support from the TB patient-fund, some patients received home visits from the volunteers. The criteria for a home visit included: extremely poor TB patients, living alone, living with 
Table 1. Treatment outcome of tuberculosis patients receiving financial support from the patient-fund, classified by ethnicity (June 2009 to March 2011)

\begin{tabular}{|c|c|c|c|c|c|c|c|c|}
\hline \multirow{2}{*}{ Patients' ethnicity } & \multicolumn{2}{|c|}{$\begin{array}{l}\text { Receiving financial } \\
\text { support }\end{array}$} & \multicolumn{4}{|c|}{ Tuberculosis treatment outcome $(\%)^{*}$} & \multirow{2}{*}{ RR (95\% Cl) } & \multirow{2}{*}{$p$-value } \\
\hline & (Yes/No) & $n$ & $\begin{array}{l}\text { Success } \\
\text { rate }\end{array}$ & Death & $\begin{array}{l}\text { Treatment } \\
\text { failure }\end{array}$ & Default & & \\
\hline \multirow{2}{*}{ Thai } & Yes & 104 & 72.1 & 23.1 & 0 & 4.8 & $1.42(1.24-1.67)$ & \multirow{2}{*}{$P<0.0$} \\
\hline & No & 443 & 50.1 & 37.4 & 2.3 & 10.2 & Reference & \\
\hline \multirow{2}{*}{ Hill tribe minorities } & Yes & 75 & 72.0 & 10.7 & 2.7 & 14.7 & $1.12(0.94-1.47)$ & \multirow{2}{*}{$P=0.1$} \\
\hline & No & 85 & 61.2 & 16.5 & 4.7 & 17.7 & Reference & \\
\hline \multirow{2}{*}{ Migrants } & Yes & 13 & 30.8 & 7.7 & 0 & 61.5 & $0.75(0.31-1.84)$ & \multirow{2}{*}{$P=0.5$} \\
\hline & No & 39 & 41.0 & 36.0 & 0 & 23.1 & Reference & \\
\hline \multirow{2}{*}{ Totals } & Yes & 192 & 69.3 & 17.2 & 1.0 & 12.5 & $1.35(1.20-1.53)$ & \multirow{2}{*}{$P<0.0$} \\
\hline & No & 567 & 51.6 & 34.2 & 2.5 & 12.2 & Reference & \\
\hline
\end{tabular}

$\mathrm{RR}$ - relative risk; $\mathrm{Cl}$ - confidence interval

* Success rate - cured and completed treatment; Default - lost to follow-up > 2 months

Note: Data from Chiang Rai Hospital's TB register and TB patient-fund register.

elderly caregivers or being isolated from the community and patient consent to home visit. In each visit, four to six volunteers visited the patient at home. The volunteers usually brought milk, eggs, clothes and cash to support the patient. The volunteers gave encouragement to patients to overcome their disease and difficulties. Each home visit lasted about 30 minutes.

\section{Evaluation}

After implementing these activities for more than 15 months, we analysed the TB register and patientfund records and evaluated TB treatment outcomes of patients receiving and not receiving financial support. A group discussion with the members (10 women) who most frequently joined the activities was organized to explore the volunteers' motivations and challenges.

\section{OUTCOME}

\section{TB treatment outcome of patients receiving only financial support}

Of the total 759 TB patients, $72.1 \%, 21 \%$ and $6.9 \%$ were Thai, hill tribe, and migrant patients, respectively (Table 1). Nineteen per cent of Thai, $47 \%$ of hill tribe and $25 \%$ of migrant TB patients received financial support from the TB patient-fund. The overall treatment success rate of patients who received financial support was significantly higher than patients who did not receive financial support (relative risk [RR]:1.35;
95\% confidence interval [Cl]: $1.20-1.53 ; P<0.000$ ). Lower death rates in all groups were also observed among patients receiving financial support. However, financial assistance alone neither increased treatment success nor reduced default for migrant patients. The proportion of hill tribe patients who received support had higher treatment success and lower default rates compared to patients who did not receive support, but this was not significantly different. In addition to supporting the patients, the patient-fund also supported the travel for 26 children with close contact to TB patients, access to TB screening and TB preventive therapy.

\section{TB treatment outcome of patients receiving financial support and home visit}

Between June 2009 and March 2011, 37 patients (five children, 17 women and 15 men) were visited by the volunteers at home. They were 25 Thai, eight hill tribe and four migrant patients. Sixteen patients (43\%) had TB with HIV co-infection. Remarkably, although these patients were considered to be either very poor or having complicated psychosocial issues, the treatment success rate of these 37 patients was 95\%; two cases died (both were Thai, HIV-positive) and none defaulted. This project was not able to determine the reasons for the high treatment success of these patients. Some patients, especially the patients living alone or patients who were isolated from family and community reported feeling honoured and grateful to have the volunteers visit. One senior male patient living alone said, "It's just like a 
dream, I have never thought this will happen to my life. Several people came to visit me...Thank you...Thank you so much."

\section{Characteristics of the women volunteers, their motivations and challenges}

Since June 2009, the women's organizations that have consistently supported TB patients in Chiang Rai have been the Red Cross Chapter, the Model-Mother group, the Women's Cultural Promotion Association, the Women Volunteer for Civil Defence Association and the Senior Smart-brain volunteers. The Business and Professional Women's Association has participated with annual donations to the patient-fund. About 36 women regularly participated in the volunteer activities. More than half of the volunteers were aged over 60 years (range: 37-79 years old) and had university educations. They were retired senior government officers, health staff members, business owners or wives of high-level officials such as the governor and the hospital director. Most volunteers originated and lived in Chiang Rai. The majority of these women were members of two to five women's or volunteer organizations. Many of them knew each other and had volunteered together for many years. Some women had experience visiting disaster victims or disabled people. However, visits to TB patients' homes were new to all of them.

The volunteers found home visits challenging due to bad road conditions, especially in the rainy season. Several senior women said their family asked them not to visit patients' houses for fear of TB transmission. However, the volunteers felt home visits substantially encouraged patients and family members. Volunteers felt that their home visits may have also helped reduce TB and HIV stigma because community people observed the women visit the patients at home and interact as friends.

Group discussion with the volunteers showed that the major reasons for volunteering and supporting poor TB patients were Buddhism and the traditional Thai value that doing charity is a virtue. They plan to serve as volunteers as long as their physical health allows.

\section{DISCUSSION}

To our knowledge, this is the first report from a TB highburden country in which women with high socioeconomic status have been involved in TB care for fund-raising and home visits. Although studies from Bangladesh, Indonesia, ${ }^{8}$ India ${ }^{9}$ and Iraq $^{10}$ reported the important role of women volunteers as treatment supporters for $\mathrm{TB}$, those volunteers were women living in the same community or having comparable socioeconomic status with TB patients. Several studies reported the role of financial support and social interventions in improving the TB situation for poor patients. ${ }^{11-14}$ However, published literature describing the process of implementation is lacking.

This paper fills in the current knowledge gap by describing the process of engaging women volunteers with high socioeconomic status to financially and socially support poor TB patients. Willingness by these women to support the patients was driven by presenting the TB situation, providing research data on the experiences of poor patients and the experiences of women volunteers from other countries. The motivation to follow the Japanese women volunteers may be influenced by "Japanization." It has been suggested that since 1987, Thai people seem to respect and appreciate Japan as Asia's leading country for social, economic and technological advancement. ${ }^{15}$ Mobilizing and engaging women organizations to support poor TB patients may be applicable in other settings where medical and health staff of TB services wish to support poor patients. The patients visited by women volunteers achieved very high treatment success rates despite being very poor and experiencing psychosocial difficulties. Future research should apply qualitative research to investigate the reasons for the high treatment success among patients who received home visits. A rigorous qualitative study should elicit how patients and women volunteers perceived the support.

In this paper, we report treatment outcomes from programme implementation, not from a research procedure. The stage of HIV infection, access to antiretroviral drugs and other clinical conditions may affect treatment outcome but were not available for the 
analysis. Based on the limited data and methodology, we cannot conclude the effectiveness of the financial support and home visits. However, the overall treatment success of the patients receiving support was significantly higher than that of patients not-receiving support. The analysis by ethnicity showed high default rates in hill tribe and migrant patients; financial assistance alone may not be sufficient to assist these groups complete the long-term TB treatment.

\section{Conflicts of interest}

None declared.

\section{Funding}

The double barred cross seal donation of Japan AntiTuberculosis Association (JATA) supported the women volunteer workshops and the authors (S Luangjina, J Wongyai).

\section{References:}

1. Addressing Poverty in TB Control. Options for National TB Control Programmes. Geneva, World Health Organization, 2005 (http:// whqlibdoc.who.int/hq/2005/WHO_HTM_TB_2005.352.pdf, accessed 20 September 2012).

2. Asian development outlook 2012. Confronting rising inequality in Asia. Mandaluyong City, Asian Development Bank, 2012 (http:// www.adb.org/sites/default/files/pub/2012/ado2012.pdf, accessed 20 September 2012).

3. Global Tuberculosis Report 2012. Geneva, World Health Organization, 2012 (http://www.who.int/tb/publications/global report/en/, accessed 20 September 2012).

4. Kantipong $P$ et al. Needs assessment for a tuberculosis patient Network in Chiang Rai Hospital, Thailand. The International Journal of Tuberculosis and Lung Disease, 13(12 Suppl1):s237 (abstract) (http://www.worldlunghealth.org/Conf2009/website/ assets/files/Abstract_Book_2009_Web.pdf, accessed on 20 September 201̄).
5. Moolphate $S$ et al. Having TB and having no money: narrating sequence and consequences of eight TB patients who were poor and defaulted their treatment (abstract). Proceedings of the International Conference on Qualitative Research in Nursing and Health, 2010.

6. StopTB Partnership. Geneva, World Health Organization, 2012 (http://www/stoptb.org/, accessed 28 December 2012).

7. Nampaisan $\mathrm{O}$ et al. Rapid assessment for poverty screening for and the support for poor TB and TB-HIV patients in Chiang Rai, Thailand. The International Journal of Tuberculosis and Lung Disease, 15(11 Suppl 3):S281 (abstract) (http://www. worldlunghealth.org/confLille/images/stories/AbstractBook2011_ Web.pdf, accessed 20 September 2012).

8. Community contribution to TB care: practice and policy. Geneva, World Health Organization, 2003 (http://www.stoptb.org/assets/ documents/countries/acsm/community $\% 20$ contribution $\% 20$ to\%20tb\%20care.pdf, accessed 20 September 2012).

9. Aggarwal S. Tackling Social and Economic Determinants of Health through Women Empowerment: The SEWA Case Study (Draft). New Delhi, World Health Organization Regional Office for South-East Asia, 2008 (http://www.who.int/social_determinants/ resources/isa_sewa_ind.pdf, accessed 20 September 2012).

10. Niazi AD, Al-Delaimi AM. Impact of community participation on treatment outcomes and compliance of DOTS patients in Iraq. Eastern Mediterranean Health Journal, 2003, 9:709-717. pmid: 15748068

11. Boccia $D$ et al. Cash transfer and microfinance interventions for tuberculosis control: review of the impact evidence and policy implications. International Journal of Tuberculosis and Lung Disease, 2011, 15(6):S37-49. doi:10.5588/ijtld.10.0438 pmid:21740658

12. Rocha $\mathrm{C}$ et al. The Innovative Socio-economic Interventions Against Tuberculosis (ISIAT) project: an operational assessment. International Journal of Tuberculosis and Lung Disease, 2011, 15(Suppl 2):S50-77. doi:10.5588/ijtld.10.0447 pmid:21740659

13. Lagarde $M$, Haines A, Palmer N. The impact of conditional cash transfers on health outcomes and use of health services in low and middle income countries (Review). The Cochrane Library, 2009, Issue 4 (http://apps.who.int/rhl/reviews/CD008137.pdf, accessed 20 September 2012).

14. Benatar SR, Upshur R. Tuberculosis and poverty: what could (and should) be done? The International Journal of Tuberculosis and Lung Disease, 2010, 14:1215-1221. pmid:20843410

15. Satayanurak A. Japanization [in Thai]. Bangkok, The Open Books Publisher, 2005. 